\section{Useful adjuncts to a rehabilitation programme}

\section{Dear Sir}

I would like to mention, for hospitals not yet familiar with them, two useful adjuncts to a rehabilitation programme, Domestic Day Training and Group Training Homes.

The Day Patient Training Course is aimed at assessing, and training in self-care and social independence, patients who are at risk, for example, chronic schizophrenics living with ageing parents. Patients are referred to this course from the social workers in the community, general practitioners and other consultants. The final assessment after this course may recommend that in a sudden failure of domestic support the patient could be admitted either directly to a group home or other sheltered accommodation, or to a group training home for assessment, or may have to be admitted to the Rehabilitation Unit initially. It is hoped that some patients may have become able to cope on their own, and in any case it is aimed at preventing admissions to acute admission wards for purely social reasons.

Group Training Homes form a useful halfway house for patients proceeding from rehabilitation wards to the community. They are private houses in normal residential areas, and groups of patients can be assessed for their compatibility and their suitability for Homes.

In most of our Group Homes, one or two patients function as housekeepers and are responsible for catering and housekeeping. The Group Training Home gives them valuable experience, as the residents are paid a weekly sum in lieu of food, laundry etc., which they pay to their housekeeper. At this stage mistakes are more easily remedied and more satisfactory groups constructed than when they have moved on.

\section{News Items}

\section{American Psychiatric Association's Commission on Psychiatric Therapies}

A Commission on Psychiatric Therapies has been established by the American Psychiatric Association to examine critically the whole range of therapies in current use in the United States, and to establish guidelines 'for the practice of therapies at various points in time for psychiatric patients with given mental disorders, and with specified physical and psycho-social characteristics'. The College has been invited to act as a consultant in offering comments and criticisms on the work of the Commission. In March, 1980 a preliminary paper outlined the aims of the Commission, the extent of the project, and the general principles on which its work would be organized.

A second document, recently received, describes in detail the proposed administrative arrangements to produce a Psychiatric Treatment Manual. Such guidelines will be based
We have found this system has had advantages in assessing residents particularly regarding the following: (1) ability to continue self-medication in an unsupervised situation; and (2) co-operation in sharing household chores, in paying their housekeepers their money regularly, and practising give and take with regard to television etc.

Supervision is limited to the continuing domestic training by the occupational therapist for the housekeepers, a weekly visit from the community nurse for the purpose of giving depot drugs to the patients who do not attend the hospital by day, and a weekly visit from the Rehabilitation Sister or Charge Nurse in the evenings, when the group can be seen as a whole, to try to assess possible tensions.

Apart from the housekeeper, the residents may go out to work when jobs are available or attend hospital for work in the Industrial Therapy or other hospital departments daily, having a good mid-day meal and then supper at the Group Home. The non-housekeepers are also taught sufficient domestic skills so that the home can carry on if the housekeepers are incapacitated, and at one.time or another the trainees may have to cope with ordinary physical illness. They register with a local general practitioner who prescribes for physical illness, although the prescriptions are dealt with through the hospital as the residents are technical in-patients and so are on reduced benefit. It is probable that many hospitals already have these facilities, but for those who have not we have found them a useful adjunct to the Rehabilitation Unit.

JOAN I. HUdSON

Coney Hill Hospital

Gloucester

on both research findings and expert clinical judgement, offered by 20 Advisory Committees. Each will consist of a Chairman and four panel members, each of whom will be an acknowledged expert in the category of psychiatric disorder which that particular group will examine. The Committees will make every attempt to reach a consensus before submitting a 'Narrative'. The 'Narratives' will then be edited and the First Draft of the Psychiatric Treatment Manual will be given a field trial to determine its clarity, acceptablity and usefulness. Participants in the trial will be asked to respond to a questionnaire after using it in the treatment of patients for a period of at least one month.

The responses to the questionnaire will form the basis of a revision of the Treatment Manual which will then be sent to a sample of 100 clinicians who have had no previous involvement in the project. Their report will form the basis of a further revision which will then be sent to the APA Board of Trustees for endorsement. 